\section{Quality of life and its association with work, the Internet, participation in groups and physical activity among the elderly from the EpiFloripa survey, Florianópolis, Santa Catarina State, Brazil}

\author{
Qualidade de vida e a associação com trabalho, \\ Internet, participação em grupos e atividade física \\ em idosos do Estudo EpiFloripa, Florianópolis, \\ Santa Catarina, Brasil
}

\author{
Calidad de vida y asociación con el trabajo, \\ Internet, participación en grupos y actividad física \\ en ancianos del Estudio EpiFloripa, Florianópolis, \\ Santa Catarina, Brasil
}

\begin{abstract}
The study aimed to investigate the association between changes in social relations and physical activity on the quality of life of the elderly in the city of Florianópolis, Santa Catarina state, Brazil. Data on 1,197 elderly from two waves of the population and household survey, EpiFloripa Idoso, were analyzed. Multiple linear regression was performed to estimate association of social change variables and lifestyle on quality of life score (QoL; measured by CASP-16 Brazil, score can range from 0 , which represents no QoL to 48, total satisfaction in all domains of CASP). The average QoL score in the sample was 37.6 (95\%CI: 37.2; 38.1). The social relations that were associated with positive QoL score were to start to work, to continue to use the Internet, to start participating in religious or lifestyle groups, to remain and to become physically active, and for those who were physically active, but became inactive in the second wave. To remain living with family had a negative effect on QoL score for the elderly. Some changes in social relations had a positive effect on QoL, and results reaffirmed the importance of physical activity to healthy aging, since to pursue it in some of the waves was better than to remain inactive.
\end{abstract}

Quality of Life; Aged; Social Networking; Motor Activity
Larissa Pruner Marques 1 Ione Jayce Ceola Schneider 1 Eleonora d'Orsi 1

doi: 10.1590/0102-311X00143615

\author{
${ }_{1}$ Departamento de Saúde \\ Pública, Universidade \\ Federal de Santa Catarina, \\ Correspondence \\ L. P. Marques \\ Departamento de Saúde \\ Pública, Universidade Federal \\ de Santa Catarina. \\ Rua Delfino Conti $s / n$, \\ Florianópolis, SC 88036-020, \\ Brasil. \\ larissapm_90@hotmail.com
}




\section{Introduction}

Population aging is one of the most significant trends of the century and is considered a triumph of development. According to the United Nations, in 2012 the proportion of people aged 60 or more was higher than those aged under five. By 2050, this number is expected to be greater than the population under 151 .

Among the causes for these demographic changes, among the factors contributing towards greater human longevity, the ones that stand out include health conditions and the possibility of developing other interests, such as ways to improve their quality of life (QoL) 2,3. According to Maslow's theory on human needs 4 , the concept of QoL for the elderly is defined by satisfaction in four areas: control, or the ability to actively intervene in one's environment; autonomy, or the right of an individual to be free from the unwanted interference of others; self-realization; and pleasure, which is an active and reflexive process of being human 5,6. Based on this theory, the instrument Control, Autonomy, Self-realization and Pleasure (CASP) was developed to evaluate QoL in the elderly, from an active and positive perspective within the ageing process 5 .

The presence of QoL goes beyond health. It is not only associated with the evolution of technology and medicine, but with other factors, such as participation in lifestyle, religious, exercise or working groups. This interaction in groups involves emotional, behavioral and physical aspects, and is perceived as a way of keeping active during the aging process and of performing a socially important activity, thereby providing a better QoL 7,8 .

High levels of social activity make older adults less likely to face cognitive decline. Structural aspects of social relations, for example living arrangements, are related to high levels of cognitive function. In addition, people with a strong social network have a lower risk of morbidity and mortality 9 .

The environment can also encourage the elderly to have contact with friends and to provide a sense of being part of a place 7,8. Authors identified that good QoL, from the points of view of the elderly, was mainly linked to social relations ?. Similarly, others reaffirmed the predictive role of social relations and physical activity on increased levels of QoL among the elderly 10,11,12.

A study on the effect of changing factors on QoL of the elderly makes it possible to assess whether it is still possible to intervene at this point in life, and to provide better conditions for this age group. While some perceive this age as the end stage, others point out that age itself is almost irrelevant 13 .
Tampubolon 11 note that only a few empirical studies have evaluated changes throughout life. And Jenkins \& Mostafa ${ }^{3}$ emphasize the importance of quantitative studies for the understanding of QoL, as it makes it possible to access representative samples and to estimate measures of effect.

The objective of this study was to investigate the association of changes in social relations and physical activity on QoL among the elderly living in the city of Florianópolis, Santa Catarina State, Brazil, between 2009/2010 and 2013/2014.

\section{Materials and methods}

This cross-sectional study is part of a longitudinal, population and home based study, called EpiFloripa Idoso. It was conducted with residents aged over 60 living in the urban area of Florianópolis, the capital city of Santa Catarina State in Southern Brasil. The first wave of the study took place between September 2009 and June 2010, and the second wave between November 2013 and November 2014.

The sample selection from baseline occurred in two stages by cluster. The first unit was the census tracts. From the 420 urban sectors of Florianópolis, 80 were drawn systematically, which corresponded to eight sectors in each income decile (BRL 192.80 - BRL 13,209.50). The units for the second stage were the households. An update step of their number in each sector (enrollment) was necessary and only the permanently occupied residential addresses were registered. The number of households ranged from 61 to 725 , and to reduce the coefficient of variation, from $52.7 \%$ ( $n=80 \mathrm{sec}$ tors) to $35.2 \%$ ( $\mathrm{n}=83$ sectors), a grouping of small sectors was carried out, taking into consideration the geographical location and the corresponding income decile, and the division of very large areas. It was estimated that 60 households per sector would need to be visited, in order to meet with 20 seniors, also selected systematically.

The sample size estimation was performed using the EpiInfo program, version 6.04 (Centers for Disease Control and Prevention, Atlanta, U.S.A.). It was based on the formula for calculating prevalence and the parameters of the size of the population $(44,460)$, confidence level $(95 \%)$, unknown prevalence $(50 \%)$, sampling error (4 percentage points), design effect (estimated at 2), plus $20 \%$ for estimated losses and $15 \%$ for association studies. This resulted in a minimum sample of 1,599 individuals. The sample was extended to 1,911 elderly, due to the availability of funds, but 1,702 elderly were interviewed.

The study participants were elderly men and women aged 60 or older. The exclusion criteria 
used only in the first wave was those who were residing in an institution (a nursing home, hospital or prison). For both waves, a loss was considered to be when the participant had not been located after four visits at different times, and a refusal when the participant showed no interest in the research. During the second wave, a loss was when the participant was unable to be contacted because of travel, hospitalization or death.

For the second wave an active search for all the elderly was organized using telephone contacts, letters, posters, electronic media and health information systems. From 1,702 respondents in the first wave, we identified 376 losses $(22,1 \%)$, which included 217 deaths, and 129 refusals $(7,6 \%)$, totaling 1,197 participants in 2013/2014 (response rate of $70.3 \%$ ).

For the present study, the inclusion criteria was participation in both waves. Exclusion criteria was interview answered by an informant (someone responsible for the elderly) or unanswered items among the outcome variables.

The data were collected by means of individual interviews that were conducted by trained interviewers. Validated instruments were used and a pilot study was developed ( $\mathrm{n}=99$ in the first wave and $n=76$ in the second). In 2009/2010 the interviews were recorded using portable digital devices (PDA), and in 2013/2014 using netbooks.

A quality control of EpiFloripa Idoso was carried out by applying a reduced questionnaire by telephone (with eight questions) among about $10 \%$ of the elderly in the sample, who were selected at random. The reproducibility of the questions showed satisfactory to good agreement (first wave, kappa of between 0.6 and 0.9 ; and second wave, kappa of between 0.5 and 0.9 ).

The outcome of this study, QoL, was evaluated by CASP-16 Brazil 6 only at the second wave of EpiFloripa. The instrument is organized into four domains and distributed across 16 items: control (4 items), autonomy (5 items), self-realization (4 items) and pleasure (3 items). The domains have the same level of importance, thus are not hierarchically arranged 5. Each item has four response options (often, sometimes, rarely or never), and for each answer is given a score. The score can range from 0 , which indicates no QoL, to 48, which represents total satisfaction in all domains 6 .

The self-report nature of CASP-16 was considered by giving a printed version to the participant, in order for them to follow the items. The interviewer would read each item and the participant would articulate the answer. For those who could not read $(7.1 \%)$ the interviewer read the items, although this did not affect the results significantly.

The independent variables, also used as adjustments were: sex (female and male); age (60 to 69 years, 70 to 79 years and 80 years or more); education (no formal education, 1 to 4 years, 5 to 8 years, 9 to 11 years and 12 years or more) and; probable cognitive deficit (no and yes). These variables related to the second wave of EpiFloripa. Marital status (remained without a partner, changed status or remained with a partner) characterized as a change, was developed based on the two waves of the study and used as an adjustment.

The independent variables about change in social relations were organized from the two waves. They included family arrangements (remained living alone, remained living with family, moved alone and moved in with family or a caregiver); paid work (remained not working, stopped working, remained working and started working); Internet use (remained not using, stopped using, remained using and started using) and; participation in religious or lifestyle groups (remained without participating, stopped participating, remained participating and started participating).

The change in lifestyle was characterized by physical activity during leisure time (remained insufficiently active, remained sufficiently active, became insufficiently active and became sufficiently active), also from the two waves of EpiFloripa.

The Mini-Mental State Examination (MMSE) 14 assessed the cognitive deficit, a scale that ranges from zero to 30 points. For probable cognitive deficit classification the level of education was used to define the cutoff points, $19 / 20$ for the elderly without formal education and 23/24 for those with formal education 14. The International Physical Activity Questionnaire (IPAQ) 15 measured physical activity during leisure time. Participants who reported less than 150 minutes per week were considered to be insufficiently active, and those who practiced 150 minutes or more per week to be physically active 15 .

The analysis considered the sample weights. The descriptive analyses of the qualitative variables were performed through absolute and relative frequencies, and the outcome with a measure of central and dispersion tendency. QoL was expressed as mean and 95\% confidence intervals (95\%CI), according to the independent variables. The means were compared using the Mann-Whithey test, and Kruskal-Wallis and nonparametric trend tests were performed for the variables age and education.

The crude and adjusted analysis used multiple linear regression and results were given in standardized beta $(\beta)$ coefficient and their respective $95 \%$ CI. At the adjusted analysis, each variable of change in social relations and physical activity was controlled by demographic, socioeconomic and probable cognitive deficit, in order 
to estimate their effect on the QoL score. The level of statistical significance for association was set at $5 \%$.

In order to test the residuals, the standard residuals, Ramsey Reset test and variance inflation factor were verified. A sensitivity analysis was carried with the QoL domains. All these analyses were performed using the use of Stata 11.0 software for Windows (Stata Corp., College Station, U.S.A.).

The Ethics Committee for Human Beings (CEPSH) at Santa Catarina Federal University (UFSC) approved the EpiFloripa Idoso study. The baseline was approved under protocol number 352/2008, dated 23 December 2008, and the second, under the CAAE 16731313.0.0000.0121, dated 9 July 2013.

\section{Results}

For the present study, 57 (4.7\%) of the 1,197 respondents from the second wave were excluded because the interview was answered by an informant; two $(0.2 \%)$ refused to answer the QoL instrument; and seven $(0.6 \%)$ did not answer an item from CASP-16. Overall, this made for a total of 66 losses. Among these losses, 48 (72.7\%) were female, $42(63.6 \%)$ were aged 80 or more and 25 (39.1\%) had 1 to 4 years of education. The sample used for analysis included 1,131 elderly (response rate of $94.5 \%$ ).

Participants from the second wave were predominantly female, aged 70 to 79 , had 1 to 4 years of education and no probable cognitive deficit. Among the waves of the study, over half of the elderly remained with their partner (54.2\%), were living with their family (76.6\%) and did not work (77.9\%). Other majority groups included elderly who remained without using the Internet (69\%), had stopped participating in religious or lifestyle groups (41.7\%) and remained insufficiently active (56.7\%) (Table 1).

The QoL mean score was 37.6 (95\%CI: 37.2; 38.1). There was no statistical difference between sex and marital status. The age and education groups with the highest scores, respectively, were 60 to 69 years and 12 or more years of study, both showing a linear trend. The average QoL score was higher among older people with no probable cognitive deficit. With regard to variables about changes in social relations, those who remained living alone, began to work, continued to use the Internet and began to join groups had the highest scores of QoL. Among those who remained and became physically active, the mean score was 41.5 (95\%CI: 40.7; 42.4) and 40.1 (95\%CI: 38.9; 41.1), respectively (Table 1).
The crude analysis showed that the elderly who continued living with the family reduced QoL by 1.98 points (95\%CI: $-3.47 ;-0.50)$, compared to those who remained living alone. The ones who started and remained working had the highest points added to the score, 2.30 (95\%CI: $0.45 ; 4.16)$ and 3.90 (95\%CI: 2.36; 5.44), respectively. As for the Internet, further use was associated with higher QoL score, compared to the ones who remained without using it. All categories of physical activity were associated with positive scores of QoL compared to the ones who remained insufficiently active (Table 2).

In the adjusted analysis, the elderly who remained living with the family lowered the score at 3.33 points $(95 \% \mathrm{CI}:-5.06$; -1.60$)$ compared to the elderly who continued to live alone. To keep working lost its association after adjustment, however the ones who started to work, between 2009/2010 and $2013 / 2014$, remained associated with a positive score of QoL ( $\beta=2.82,95 \% \mathrm{CI}$ : $1.42 ; 4.22)$ (Table 2).

Participants who continued using the Internet had 2.11 more points $(95 \% \mathrm{CI}: 0.85$; 3.36$)$ in their QoL score than those who never used it. Older people who began participating in groups exhibited a higher QoL score by 1.68 points $(95 \% \mathrm{CI}$ : $0.19 ; 3.17$ ), compared to those who remained without participating. For physical activity, all categories continued to show association, and with little change after adjustment. The elderly who remained physically active had more points in QoL score ( $\beta=4.47,95 \% \mathrm{CI}: 3.32 ; 5.63)$, compared to the group that remained insufficiently active. The elderly who in the first wave were sufficiently active, but became insufficiently active, still had higher scores when compared with those who remained insufficiently active (Table 2).

According to the standard residuals there are no specification errors in the regression models for the analysis, and $95 \%$ of the residuals were between the range of $-2,2$ and normal distribution, giving the Gauss curve. The Ramsey Reset test showed there to be no omitted variables in the regression models; and no multicollinearity using the variance inflation factor.

The sensitivity analysis with sub-scores of QoL domains showed that there was an association only for those who moved with their family or a caregiver (control's domain: $\beta=-0.39,95 \% \mathrm{CI}$ : $-1.75 ;-0.06)$ and those who remained working (pleasure's domain: $\beta=0.38,95 \% \mathrm{CI}$ : $0.21 ; 0.55$ ). These results did not show a reverse association, which supports the use of an overall score for QoL. 
Table 1

Descriptive analysis and quality of life mean score according to demographic, economic, changes in social relations and physical activity for the elderly indicators. EpiFloripa Idoso, Florianópolis, Santa Catarina State, Brazil, 2009/2010 and 2013/2014.

\begin{tabular}{|c|c|c|c|}
\hline Variable & $n(\%)$ & QoL mean score $(95 \% \mathrm{Cl})$ & p-value \\
\hline $\operatorname{Sex}[n=1,131]$ & & & 0.107 * \\
\hline Female & $730(64.5)$ & $37.3(36.8 ; 37.9)$ & \\
\hline Male & $401(35.5)$ & $38.2(37.5 ; 38.9)$ & \\
\hline Age (years) $[n=1,131]$ & & & $<0.001 * *$ \\
\hline $60-69$ & $400(35.4)$ & $39.0(38.4 ; 39.7)$ & \\
\hline $70-79$ & $497(43.9)$ & $37.6(36.9 ; 38.3)$ & \\
\hline 80 or more & $234(20.7)$ & $35.4(34.4 ; 36.6)$ & \\
\hline Education (years) $[n=1,130]$ & & & $<0.001$ **,\# \\
\hline No formal education & $80(7.1)$ & $36.1(34.3 ; 38.0)$ & \\
\hline $1-4$ & $405(35.8)$ & $36.7(35.9 ; 37.5)$ & \\
\hline $5-8$ & $190(16.8)$ & $37.3(36.3 ; 38.4)$ & \\
\hline $9-11$ & $175(15.5)$ & $38.4(37.3 ; 39.5)$ & \\
\hline 12 or more & $280(24.8)$ & $39.2(38.4 ; 39.9)$ & \\
\hline Cognitive deficit $[n=1,125]$ & & & $<0.001$ * \\
\hline No & $864(76.8)$ & $38.5(38.0 ; 39.0)$ & \\
\hline Yes & $261(23.2)$ & $34.9(33.8 ; 35.9)$ & \\
\hline Marital status $[\mathrm{n}=1,131]$ & & & 0.279 ** \\
\hline Remained without a partner & $422(37.3)$ & $37.4(36.6 ; 38.2)$ & \\
\hline Changed status & $96(8.5)$ & $38.5(36.8 ; 40.0)$ & \\
\hline Remained with a partner & $613(54.2)$ & $37.7(37.1 ; 38.2)$ & \\
\hline Family arrangement $[n=1,115]$ & & & $0.002 * \star$ \\
\hline Remained living alone & $146(13.1)$ & $39.8(38.7 ; 40.8)$ & \\
\hline Remained living with family & $854(76.6)$ & $37.3(36.8 ; 37.9)$ & \\
\hline Moved alone & $84(7.5)$ & $38.5(36.9 ; 40.0)$ & \\
\hline Moved to with family or caregiver & $31(2.8)$ & $37.2(34.2 ; 40.0)$ & \\
\hline Paid work $[n=1,030]$ & & & $<0.001$ ** \\
\hline Remained not working & $802(77.9)$ & $37.2(36.7 ; 37.7)$ & \\
\hline Stopped working & $98(9.5)$ & $38.9(37.3 ; 40.2)$ & \\
\hline Remained working & $76(7.4)$ & $40.3(38.9 ; 41.6)$ & \\
\hline Started working & $54(5.2)$ & $41.1(39.8 ; 42.3)$ & \\
\hline Internet $[\mathrm{n}=1,131]$ & & & $<0.001 * *$ \\
\hline Remained not using & $781(69.0)$ & $36.8(36.3 ; 37.4)$ & \\
\hline Stopped using & $34(3.0)$ & $38.3(35.4 ; 40.8)$ & \\
\hline Remained using & $227(20.1)$ & $40.5(39.8 ; 41.3)$ & \\
\hline Started using & $89(7.9)$ & $37.4(35.7 ; 39.1)$ & \\
\hline Groups [n = 1,131] & & & $<0.001 * *$ \\
\hline Remained without participating & $185(16.4)$ & $37.5(36.3 ; 38.5)$ & \\
\hline Stopped participating & $472(41.7)$ & $36.5(35.7 ; 37.2)$ & \\
\hline Remainde participating & $131(11.6)$ & $38.5(37.2 ; 39.7)$ & \\
\hline Started participating & $343(30.3)$ & $39.0(38.4 ; 39.7)$ & \\
\hline Physical activity $[\mathrm{n}=1,131]$ & & & $<0.001 * *$ \\
\hline Remained insufficiently active & $641(56.7)$ & $36.0(35.4 ; 36.6)$ & \\
\hline Remained sufficiently active & $175(15.5)$ & $41.5(40.7 ; 42.4)$ & \\
\hline Became sufficiently active & $136(12.0)$ & $40.1(38.9 ; 41.1)$ & \\
\hline Became insufficiently active & $179(15.8)$ & $38.0(37.0 ; 39.0)$ & \\
\hline
\end{tabular}

95\%Cl: 95\% confidence interval; QoL: quality of life.

* Mann-Whitney test;

** Kruskal-Wallis test;

\# Tendency, according to nonparametric trend test for ordinal groups. 
Crude and adjusted analysis of quality of life according to changes in social relations and physical activity for the elderly. EpiFloripa Idoso, Florianópolis, Santa Catarina State, Brazil, 2009/2010 and 2013/2014.

\begin{tabular}{|c|c|c|c|c|}
\hline \multirow[t]{2}{*}{ Variable } & \multicolumn{2}{|c|}{ Crude analysis } & \multicolumn{2}{|c|}{ Adjusted analysis * } \\
\hline & $\beta(95 \% \mathrm{Cl})$ & p-value & $\beta(95 \% \mathrm{Cl})$ & p-value \\
\hline Family arrangement $[n=1,115]$ & & 0.061 & & $<0.001$ \\
\hline Remained living alone & 0.00 & & 0.00 & \\
\hline Remained living with family & $-1.98(-3.47 ;-0.50)$ & & $-3.33(-5.06 ;-1.60)$ & \\
\hline Moved alone & $-0.65(-2.97 ; 1.68)$ & & $-1.25(-3.55 ; 1.06)$ & \\
\hline Moved with family or caregiver & $-1.66(-4.80 ; 1.49)$ & & $-1.57(-4.36 ; 1.23)$ & \\
\hline Paid work $[n=1,030]$ & & $<0.001$ & & $<0.001$ \\
\hline Remained not working & 0.00 & & 0.00 & \\
\hline Stopped working & $1.41(-0.08 ; 2.90)$ & & $0.86(-0.62 ; 2.33)$ & \\
\hline Remained working & $2.30(0.45 ; 4.16)$ & & $0.92(-0.94 ; 2.78)$ & \\
\hline Started working & $3.90(2.36 ; 5.44)$ & & $2.82(1.42 ; 4.22)$ & \\
\hline Internet $[\mathrm{n}=1,131]$ & & $<0.001$ & & $<0.001$ \\
\hline Remained not using & 0.00 & & 0.00 & \\
\hline Stopped using & $0.81(-2.65 ; 4.28)$ & & $0.13(-3.12 ; 3.38)$ & \\
\hline Remained using & $3.33(2.28 ; 4.39)$ & & $2.11(0.85 ; 3.36)$ & \\
\hline Started using & $-0.63(-2.33 ; 1.08)$ & & $-1.36(-3.33 ; 0.62)$ & \\
\hline Groups [n = 1,131] & & 0.003 & & $<0.001$ \\
\hline Remained without participating & 0.00 & & 0.00 & \\
\hline Stopped participating & $-0.77(-2.38 ; 0.83)$ & & $-0.89(-2.46 ; 0.69)$ & \\
\hline Remained participating & $1.46(-0.58 ; 3.49)$ & & $1.19(-0.68 ; 3.06)$ & \\
\hline Started participating & $1.43(-0.10 ; 2.95)$ & & $1.68(0.19 ; 3.17)$ & \\
\hline Physical activity [ $n=1,131]$ & & $<0.001$ & & $<0.001$ \\
\hline Remained insufficiently active & 0.00 & & 0.00 & \\
\hline Remained sufficiently active & $5.22(3.96 ; 6.48)$ & & $4.47(3.32 ; 5.63)$ & \\
\hline Became sufficiently active & $4.02(2.34 ; 5.70)$ & & $3.58(1.95 ; 5.21)$ & \\
\hline Became insufficiently active & $1.78(0.37 ; 3.23)$ & & $1.67(0.26 ; 3.08)$ & \\
\hline
\end{tabular}

95\% Cl: 95\% confidence interval; $\beta$ : beta standardized regression coefficient.

* Model adjusted for sex, age, education, cognitive deficit and marital status.

\section{Discussion}

The mean QoL score for the elderly from the EpiFloripa 2013/2014 was 37.6 (95\%CI: 37.2; 38.1). The variable categories which had positive scores for QoL were: to start working compared to those who remained retired; to continue using the Internet compared to those who did not use it; to remain or become physically active; and to become insufficiently active, compared to those who remained inactive. However, the family arrangements whereby the elderly remained living with family had a negative association to their QoL when compared with those who remained living alone.

Results from the first wave of the English Longitudinal Study of Ageing (ELSA), involving 11,234 people over the age of 50 found a mean QoL score, assessed by CASP-19, of 42.5 (95\%CI: 42.3; 42.7) CASP-19 is the original QoL instrument with scores ranging from zero to 57 . In the context of Brazil, three items were excluded for better psychometric properties 10. The QoL score of the elderly from the city of Florianópolis was found to be closer to the maximum value of CASP-16, in spite of the limitations involved in comparing scores, given the different structures.

The elderly who remained living with their family had fewer points in the QoL score compared to those who continued living alone. The issue of family arrangements is discussed in the literature, but many studies 10,16,17,18 have not identified an association with QoL. The study by Garcias et al. 19 assessed health-related QoL with the Short Form-36 (SF-36), and found that those who lived alone had low scores in social and mental QoL. 
However, when all domains of SF-36 were considered, living alone lost its association with worse QoL related to health. In the study by Zaninotto et al. 12, for the first three waves of ELSA (2002-2007), only in the third, and just in the case of males, living with a partner had a positive effect on QoL.

The perception of age as being related to fragility means that the elderly can still be excluded from certain activities, which may contribute to their autonomy or control and are therefore important for their QoL. This may explain the lower QoL score for those who are living with family, while those who live alone may have more autonomy 20 . Another factor may be the often active role played by the family at times of illness or need. These situations are often stressful for those involved, and can provide a sense of dependence, reduce self-esteem and consequently have a negative effect on QoL 19,21. But the effect of the family structure on QoL may vary depending on the age group of the elderly person and other individual factors 22 .

The elderly who started working between the waves of the study demonstrated a greater improvement in their QoL scores compared to those who remained without work. Other studies 12,23 also observed that being unemployed had a negative impact on QoL, or in one British study, that performing paid work had a positive impact on the elderly.

Retirement can be faced in different ways and is a heterogeneous process. Historically, this has involved financial and physical decline 23 , or, from a different perspective, an opportunity to engage in other activities that the elderly enjoy 2,5. Returning to the labor market may be consistent with the desire to remain active and feel socially important. The study shows that improved QoL can be attained through the domains of control, self-realization and pleasure 7,24,25. In additional, unpublished analysis in the study, there was no predominance of low income elderly among those who started working.

The work environment can also encourage contact with friends and provide the feeling of being part of a social environment. Further, relationships with friends is found to have a better effect on the elderly's QoL compared with family. Friends can be chosen and this relationship encourages ties of trust 19 . Wahrendorf 25 highlights the importance for the elderly of returning to work after retirement.

Regarding the use of technology, this study showed that participants who kept using the Internet showed a significant increase in their QoL score. Technology represents an opportunity for greater QoL among the elderly 26. The use of a computer and the Internet can contribute to well-being and generate a greater sense of capability and self-realization. It positively affects interpersonal relationships, stimulates cognitive function and contributes to the elderly's independence $11,26,27,28,29$.

The associated category, to maintain use of the Internet, relates to issues that are specific to the elderly, including having time to learn how to use technology, having health problems or difficulties in using the Internet, which can discourage them from learning. However, limitations in the study design, and possible reverse causality also need to be taken into consideration.

Studies 27,30,31 identified associations between computer use, and related access to information, and the adoption of healthy habits such as not smoking, physical activity and a healthy diet. The work of d'Orsi et al. 28, involving 8,154 individuals from the first wave of ELSA and an empirical study by Ordonez et al. ${ }^{32}$, point out that digital inclusion may represent an important strategy for cognitive improvement and help the elderly to continue to perform daily activities independently. These living habits and conditions may take some time to take effect, which may be one of the reasons for the associated category.

There are differences in the literature regarding these claims. Slegers et al. 33 used SF-36 for a randomized controlled intervention study involving 240 elderly from Maastricht in the Netherlands and found no significant impact on well-being of learning, or use of computers or the Internet. However, those who used the computer more felt they had greater control over their lives 33 . In this comparison, different tools for QoL were used. The SF-36 and the CASP-16 use different constructs and evaluations: while CASP-16 assesses QoL itself, SF-36 addresses health-related QoL.

In the EpiFloripa, those elderly who had begun to participate in religious or lifestyle groups between the waves, showed improvements in their QoL scores. The discussion of this association involves the use of variables that are characterized by change and is limited because of a lack of information about when the participation started or finished during the waves. In addition, a small sample of elderly continued to participate in the group.

Jenkins \& Mostafa 3 linked learning to the development of autonomy and self-realization. At this age, informal activity groups, such as education, art, music and physical activity groups, significantly contribute to better QoL. However, formal training or educational courses did not show any association ${ }^{3}$. Group membership may therefore be related to the socio-emotional selectivity of the elderly, whereby they develop a strategy to engage primarily in activities that give them pleasure and satisfaction. The continuation of group 
activities may be related to the elderlies' physical or emotional conditions, or to the quality of the activities developed 10 .

The benefits of physical activity on health and QoL have been strongly established in the literature, regardless of how QoL is assessed 11,17,18,19. The elderly who remained physically active had higher QoL scores. Even those who were no longer active had a positive impact on QoL compared to those who remained insufficiently active.

A study 18 involving elderly people aged 75 and over in Gothenburg, Sweden found an association between regular walking and health-related QoL (SF-36), which remained only with a few domains (physical performance, general health, emotional aspects) and for women. This difference between genders on the level of physical activity can happen because of the physical conditions or chronic conditions of each individual 18.

The use of CASP-16 Brazil made it possible to evaluate the QoL measured directly, without using proxies, such as health-related QoL. This made it possible to distinguish between QoL and the factors that influence it. The instrument was easy to apply and was well understood by Brazilian elderly ${ }^{6}$. It focuses on the benefits and enjoyable aspects of aging, different from the negativity of the social and medical sciences which focus on the links between aging and functional and health decline 5,34. The theory on which the instrument is based assumes that the elderly can adapt their lives, even with the limitations relevant to age 5. CASP is an instrument widely used in over 20 countries and in several studies. It has proven to be important in evaluating QoL in the elderly, particularly since it allows for comparisons between countries 35 .
This research also involved the study of social relations in a large sample from a capital city in southern Brazil. There were only a few losses during follow-up, although there was a high number of deaths, which may open up the possibility that those who died were the elderly who had the worst QoL scores. This study explored the changes during the life of the elderly, but it did not look into the exact timing of changes to social relations or lifestyles. The design also has the limitation of reverse causality. Other limitations were the comparisons of final QoL scores, given the differences in the CASP structures, on account of the country-level validations. Although the CASP-16 was found to be comparable with other instruments in Brazil 6, further evaluation of its structure is required.

The subjective measurement of physical activity may lead to overestimation; however, we used a validated instrument, despite the difficulty with such an evaluation for surveys. Another limitation was that the relationships between members of the house were not explored more deeply to better understand family arrangements, as well as group activities. Considering the complexity of the outcome, other factors that are not adjusted could also influence the score.

Many important events affect the trajectory of the elderly, but this study pointed out some changes that can improve QoL for this age group. QoL for the elderly relates to the ability to adapt to difficulties that may arise. Some of the factors that contribute to quality of life include: to encourage participation in social activities; to return to work; to use the Internet and to practice physical activity. The use of CASP-16 is recent, and further studies to evaluate its structure are required. It is, nonetheless, an excellent tool for population surveys, since is made up of only a few items, and has good psychometric properties, internal consistency ${ }^{6}$ and comparability with other countries. 


\section{Contributors}

L. P. Marques conceived and wrote the manuscript. I. J C. Schneider participated in the development and review of the manuscript. E. d'Orsi reviewed and approved the final version of the manuscript.

\section{Acknowledgments}

We wish to thank the following: Brazilian Graduate Studies Coordinating Board (Capes) for the master fellowship provided to the first author; Brazilian National Research Council (CNPq, process 569834/2008 2) for the post-doctoral fellowship to the second author; the study participants for welcoming us into their homes and colleagues from EpiFloripa Idoso for their dedication to the study; in addition, the organizations Santa Catarina Federal University (UFSC), Capes and Oswaldo Cruz Foundation (Fiocruz).

\section{References}

1. United Nations Population Fund; HelpAge International. Ageing on the 21st Century: celebration and challenge. New York: United Nations Population Fund; 2012.

2. Laslett P. A fresh map of life. London: Macmillan Press Ltd.; 1996.

3. Jenkins A, Mostafa T. The effects of learning on wellbeing for older adults in England. Ageing Soc 2015; 35:2053-70.

4. Maslow AH. Toward a psychology of being. Princeton: Van Nostrand; 1968.
5. Hyde M, Wiggins RD, Higgs P, Blane DB. A measure of quality of life in early old age: the theory, development and properties of a needs satisfaction model (CASP-19). Aging Ment Health 2003; 7:18694.

6. Lima F, Hyde M, Chungkham H, Correia C, Campos AS, Campos M, et al. Quality of life amongst older Brazilians: a cross-cultural validation of the CASP-19 into Brazilian-Portuguese. PLoS One 2014; 9:e94289. 
7. Netuveli G, Blane D. Quality of life in older ages. $\mathrm{Br}$ Med Bull 2008; 85:113-26.

8. Tahan J, Carvalho ACD. Reflections of aged participating in the health promotion groups concerning the ageing and the quality of life. Saúde Soc 2010; 19:878-88.

9. Charles ST, Carstensen LL. Social and emotional aging. Annu Rev Psychol 2010; 61:383-409.

10. Netuveli G, Wiggins RD, Hildon Z, Montgomery SM, Blane D. Quality of life at older ages: evidence from the English longitudinal study of aging (wave 1). J Epidemiol Community Health 2006; 60:35763.

11. Tampubolon G. Delineating the third age: joint models of older people's quality of life and attrition in Britain 2002-2010. Aging Ment Health 2015; 19:576-83.

12. Zaninotto P, Falaschetti E, Sacker A. Age trajectories of quality of life among older adults: results from the English Longitudinal Study of Ageing. Qual Life Res 2009; 18:1301-9.

13. Lowsky DJ, Olshansky SJ, Bhattacharya J, Goldman DP. Heterogeneity in healthy aging. J Gerontol A Biol Sci Med Sci 2014; 69:640-9.

14. Almeida OP. The Mini-Mental State Examination and the diagnosis of dementia in Brazil. Arq Neuropsiquiatr 1998; 56:605-12.

15. Benedetti TB, Mazo GZ, Barros MVG. Aplicação do Questionário Internacional de Atividades Físicas para avaliação do nível de atividades físicas de mulheres idosas: validade concorrente e reprodutibilidade teste-reteste. Rev Bras Ciênc Mov 2004; 12:25-34.

16. Aghamolaei T, Tavafian S, Zare S. Health related quality of life in elderly people living in Bandar Abbas, Iran: a population-based study. Acta Med Iran 2010; 48:185-91

17. Belvis AG, Avolio M, Sicuro L, Rosano A, Latini E, Damiani G, et al. Social relationships and HRQL: a cross-sectional survey among older Italian adults. BMC Public Health 2008; 8:348.

18. Hörder H, Skoog I, Frändin K. Health-related quality of life in relation to walking habits and fitness: a population-based study of 75-year-olds. Qual Life Res 2013; 22:1213-23.

19. García EL, Banegas JR, Pérez-Regadera AG, Cabrera RH, Rodríguez-Artalejo F. Social network and health-related quality of life in older adults: a population-based study in Spain. Qual Life Res 2005; 14:511-20.

20. Wiggins RD, Higgs PFD, Hyde M, Blane DB. Quality of life in the third age: key predictors of the CASP-19 measure. Ageing Soc 2004; 24:693-708.

21. Kawachi I, Berkman LF. Social ties and mental health. J Urban Health 2001; 78:458-67.

22. Litwin H, Stoeckel KJ. Social networks and subjective wellbeing among older Europeans: does age make a difference? Ageing Soc 2013; 33:1263-81.
23. McMunn A, Nazroo J, Wahrendorf M, Breeze E, Zaninotto P. Participation in socially-productive activities, reciprocity and wellbeing in later life: baseline results in England. Ageing Soc 2009; 29:765-82.

24. d'Orsi E, Xavier AJ, Ramos LR. Work, social support and leisure protect the elderly from functional loss: epidoso study. Rev Saúde Pública 2011; 45:685-92.

25. Wahrendorf M. Previous employment histories and quality of life in older ages: sequence analyses using SHARELIFE. Ageing Soc 2015; 35:1928-59.

26. Shapira N, Barak A, Gal I. Promoting older adult's well-being through Internet training and use. Aging Ment Health 2007; 11:477-84.

27. Medeiros F, Xavier AJ, Schneider IJ, Ramos LR, Sigulem D, d'Orsi E. Digital inclusion and functional capacity of older adults living in Florianópolis, Santa Catarina, Brazil (EpiFloripa 2009-2010). Rev Bras Epidemiol 2012; 15:106-22.

28. d'Orsi E, Xavier AJ, Steptoe A, Oliveira C, Ramos LR, Orrel M, et al. Socioeconomic and lifestyle factors related to instrumental activities of daily living dynamics: results from the English Longitudinal Study of Ageing. J Am Geriatr Soc 2014; 62:1630-9.

29. Morris ME, Adair B, Kurowski EOW, Miller KJ, Pearce AJ, Santamaria N, et al. Smart technologies to enhance social connectedness in older people who live at home. Australas J Ageing 2014; 33:14252.

30. Xavier AJ, d'Orsi E, Wardle J, Demakakos P, Smith SG, Wagner CV. Internet use and cancer-preventive behaviors in older adults: findings from a longitudinal cohort study. Cancer Epidemiol Biomarkers Prev 2013; 22:2066-74.

31. Fujiwara Y, Chaves P, Yoshida H, Amano H, Fukaya T, Watanabe N, et al. Intellectual activity and likelihood of subsequently improving or maintaining instrumental activities of daily living functioning in community-dwelling older Japanese: a longitudinal study. Int J Geriatr Psychiatry 2009; 24:54755.

32. Ordonez TN, Yassuda MS, Cachioni M. Elderly online: effects of a digital inclusion program in cognitive performance. Arch Gerontol Geriatr 2011; 53:216-9.

33. Slegers K, Boxtel MPJV, Jolles J. Effects of computer training and Internet usage on the well-being and quality of life of older adults: a randomized, controlled study. J Gerontol B Psychol Sci Soc Sci 2008; 63:176-84.

34. Higgs P, Hyde M, Wiggins R, Blane D. Researching quality of life in early old age: the importance of the sociological dimension. Soc Policy Adm 2003; 37:239-52.

35. Hyde M, Higgs P, Wiggins RD, Blane D. A decade of research using the CASP scale: key findings and future directions. Aging Ment Health 2015; 19:571-5. 


\section{Resumo}

O estudo teve como objetivo investigar a associação entre mudanças nas relações sociais e na atividade física sobre qualidade de vida entre idosos na cidade de Florianópolis, Santa Catarina, Brasil. Foram analisados dados sobre 1.197 idosos de duas ondas do inquérito populacional e domiciliar, EpiFloripa Idoso. A regressão linear múltipla foi usada para estimar a associação entre variáveis de mudança social e de estilo de vida sobre qualidade de vida, medida pelo instrumento CASP-16 Brasil, com uma pontuação de zero até 48 , que representa satisfação completa em todos os domínios de qualidade de vida no CASP. A média de qualidade de vida foi 37,6 (IC95\%: 37,2; 38,1). As relações sociais associadas com pontuação alta em qualidade de vida foram iniciar um trabalho, continuação do uso da Internet, iniciar a participação em grupo religioso ou de convivência e permanecer e se tornar fisicamente ativo, e para aqueles fisicamente ativos, mas que se tornaram inativos na segunda onda. Para os idosos, continuar vivendo com familiares teve um efeito negativo sobre qualidade de vida. Algumas mudanças nas relações sociais tiveram um efeito positivo sobre qualidade de vida, e os resultados reafirmaram a importância da atividade física para o envelhecimento saudável, uma vez que a procura da vida ativa foi mais importante do que permanecer inativo.

Qualidade de Vida; Idoso; Rede Social; Atividade Motora

\section{Resumen}

El estudio tuvo como objetivo investigar la asociación entre cambios en las relaciones sociales y en la actividad física sobre la calidad de vida entre ancianos en la ciudad de Florianópolis, Santa Catarina, Brasil. Se analizaron datos de 1.197 ancianos de dos olas de la encuesta poblacional y domiciliaria, EpiFloripa Idoso. La regresión lineal múltiple se usó para estimar la asociación entre variables de cambio social y de estilo de vida sobre la calidad de vida, medida por el instrumento CASP-16 Brasil, con una puntuación de cero a 48, que representa satisfacción completa en todos los dominios de calidad de vida en el CASP. La media de calidad de vida fue 37,6 (IC95\%: 37,2; 38,1). Las relaciones sociales, asociadas con una puntuación alta en calidad de vida fueron: comenzar un trabajo, continuación en el uso de Internet, iniciar la participación en un grupo religioso o de convivencia y permanecer y convertirse en alguien físicamente activo, y para aquellos que son físicamente activos, pero que se hicieron inactivos en la segunda ola. Para los ancianos, continuar viviendo con familiares tuvo un efecto negativo sobre calidad de vida. Algunos cambios en las relaciones sociales tuvieron un efecto positivo sobre la calidad de vida, y los resultados reafirmaron la importancia de la actividad física para el envejecimiento saludable, puesto que la búsqueda de una vida activa fue más importante que permanecer inactivo.

Calidad de Vida; Anciano; Red Social,

Actividad Motora
Submitted on $02 /$ Sep/2015

Final version resubmitted on 14/Mar/2016

Approved on 22/Mar/2016 